\title{
Investment Decision-Making and Coordination of Supply Chain: A New Research in the Big Data Era
}

\author{
Pan Liu and Shu-ping Yi \\ Chongqing Key Laboratory of Logistics, College of Mechanical Engineering, Chongqing University, Chongqing 400044, China \\ Correspondence should be addressed to Shu-ping Yi; glgxx2015@163.com
}

Received 28 January 2016; Accepted 24 April 2016

Academic Editor: Allan C. Peterson

Copyright (C) 2016 P. Liu and S.-p. Yi. This is an open access article distributed under the Creative Commons Attribution License, which permits unrestricted use, distribution, and reproduction in any medium, provided the original work is properly cited.

\begin{abstract}
In a Big Data environment, in order to study the decision-making problem of Big Data information investment and the effects of using Big Data information to improve industry cost on supply chain coordination, firstly the importance of Data Company in supply chain was analyzed, and the original supply chain model was built. Meanwhile, some changes of consumer behavior were analyzed in a Big Data environment. Based on these, the market demand function and the benefit model of stakeholder were built and analyzed. Findings: (1) The first finding is whether an enterprise was suitable for gaining Big Data to improve its costs, which was determined by the cost improvement coefficient; namely, it was related to the ability of excavating and using the value of Big Data. (2) Whether the supply chain was the decentralized decision-making and the centralized decision-making, the thresholds of acquisition costs on Big Data information were equal. Moreover, the maximum value that they could undertake was same. (3) Meanwhile the fact that the quantity discount contract could achieve a win-win outcome for supply chain members was proved. The discount coefficient was related to consumers' behavior preference in a Big Data environment.
\end{abstract}

\section{Introduction}

With the rapid development of the Internet of Things (IoT) and the Cloud, global data are increasing rapidly. According to the prediction of the International Data Corporation (IDC), global data will reach $35 \mathrm{ZB}$ by 2020 [1]. Meanwhile, the development of the Cloud and virtual storage will reduce the storage cost of Big Data $[2,3]$. These developments suggest that there are opportunities for the application and development of Big Data. Therefore, the era of Big Data has arrived.

In the Big Data background, data had been called the indispensable raw materials of information economy [4] and had penetrated into every industry [5]. Unfortunately, not all enterprises are able to manage such complicated operations by themselves. So many IT executives are choosing to outsource their data. Under this condition, the position of Data Company in a supply chain will become increasingly important, which may lead to changes of the original supply chain structure. The change of supply chain structure may lead to changes of the supply chain coordination.
Meanwhile, in the era of Big Data, with the improvement of living standards, consumers' heterogeneity demand is increasing [6]. Moreover, under this new environment, consumers can easily get the information they needed, for example, the commodity prices from different sites and products evaluation from the third party. All of this will affect consumers' purchase behavior, which will lead to the change of the market demand. Finally, it will influence the benefits of a supply chain.

In a Big Data environment, many studies had described advantages of Big Data investment. However, most of them focused on qualitative researches, such as concepts and characteristics. Researchers rarely used a mathematical model to analyze the effects of a supply chain investment to obtain Big Data information (BDI) on its decision-making and coordination.

Therefore, in this paper, firstly we described that a Data Company as a "power center" held an important position in the supply chain. Then, based on this condition (i.e., there is a "power center" in the supply chain), a new supply chain model was built. Meanwhile, consumers' behavior 
preferences were discussed under the new era. Finally, under the above condition, the benefit model was constructed and analyzed.

This paper aims to analyze the investment and coordination rules of a supply chain under the condition of obtaining BDI. The results will provide the theoretical guidance for enterprises to invest in BDI and help enterprises gain more benefits and achieve victory in a competition.

\section{Related Researches}

2.1. Importance of Data Company in Supply Chain in a Big Data Environment. In a Big Data environment, supply chain will enter the data-driven era. Some practices had proved that using Big Data could help corporation operate and manage better [4]. In addition, many enterprises had used Big Data, such as Kroger, Overstock.com, and No. 1 Store [7, 8]. Therefore, the ideology of the data-driven supply chain was proposed [9-11]. The data-driven supply chain cannot lack "data;" therefore, a Data Company that acts as a "power" will play a particularly important role in the data-driven supply chain compared with the traditional supply chain.

Firstly, Data Companies are in demand because of the " $4 \mathrm{~V}$ " features of Big Data (i.e., volume, variety, velocity, and value) $[12,13]$. These characteristics brought new challenges for obtaining information. Large amounts of data are difficult for IT department to use well. According to the IDC, by 2020, the amount of global digital information would be 44 times greater than that of today [14]. Most of these data were unstructured [15]. In addition, facing the rapid updating and unstructured data, the IT department of a traditional enterprise did not have the ability to handle these data [16]. Finally, to mine the potential value of Big Data, professional IT companies needed to screening using professional Big Data technology [17].

Secondly, data quality and privacy protection need a professional Data Company. The quality of data of the supply chain would affect the supply chain members' usage of Big Data [18]. However, each link (e.g., data generation, acquisition, and transmission) is likely to affect data quality. The authenticity of the data source is an important factor that influences data quality. People protecting their privacy led to the inauthenticity of the data source [16]. Companies that protected users' privacy information were considered to be trustworthy; therefore, the user was more willing to provide personal information [19]. The professional Data Company has advantages in obtaining Big Data compared with the IT departments of the traditional enterprises.

Finally, mass customization supply chain needs Data Company support. With the improvement of living standards, the consumers' heterogeneity demand is increasing, and an individualized demand market is forming. This would lead to the traditional supply chain gradually becoming a mass customization supply chain [17]. Compared with the traditional supply chain, which focused product flow and cash flow, a mass customized supply chain was a demand-pull supply chain and focused more attention on information flow [20]. The characteristics of Big Data can meet the demand of mass customization on consumers' accurate and timely information, and the development of Big Data technology can offer effective means to extract the heterogeneity preference of consumers. This will shift the supply chain from the product "push" mode to the consumer demand data "pull" mode. At this point, the data "power center" is particularly important.

\subsection{Consumers' Behavior Preference in a Big Data Envi-} ronment. In a Big Data environment, consumers' behavior preference also produces some changes. In this paper, we only focus on two main aspects: one is the production heterogeneity demand, and the other is the preference to research the related production information.

With the improvement of living standards, the consumers' heterogeneity demand on production is increasing and the individualized demand market is forming. Therefore, stakeholders start to collect and analyze consumers' preference to obtain competitive advantages. For retailers, they analyzed the interdependency of the online purchasing behavior [21, 22] to target them with advertisements and thereby promote the overall demand. For manufacturers, they could understand, design, and meet customer needs by using Big Data [23].

However, in the Big Data era, consumers are in a world full of information. Therefore, they begin to search information to help them make decision. For example, Fang and $\mathrm{Li}$ [24] studied the effects of "Big Data" on consumer behavior. Their results indicated that information and its credibility would affect consumers' decision-making. In addition, there were two key types of information channels: one is from the commodity information, and the other is from the third-party evaluation [25]. The credibility of the third-party evaluation will influence consumers' perceived value and their decision [26]. Meanwhile, the consumers' trust on the third-party evaluation made differences, because they had a different credibility judgment [27].

Therefore, in the Big Data era, the personalization degree of products and the evaluation from the third party will influence consumers' decision and thereby affect the market demand. However, few studies focused on this; in this paper, we will do this job.

\subsection{Effects of Big Data on Supply Chain Decision-Making and} Coordination. Currently, studies focusing on the decisionmaking and coordination problems of a supply chain investment are relatively small in a Big Data environment. Existing researches are divided into qualitative researches and quantitative researches.

Qualitative researches, such as Weill and Woerner [28] and Loebbecke and Picot [22], mentioned that using Big Data could optimize production processes, promote efficiency, and reduce production cost. Wang and Alexander [11] introduced Big Data advantages and its applications in the supply chain and business management, such as improving the visibility of the supply chain, providing an integrated perspective on operating performance and customer behavior, and giving enterprises a real-time view to help them make decision. 
Groves et al. [29] explored the effects of the "Big Data" analysis on supply chain management and proposed a new method to develop a complicated decision-making strategy and an extensive set of key performance indicators. Opresnik and Taisch [30] put forward a new element for competitive advantage for manufacturer in servitization, and it was called “a Big Data strategy." Results indicated that new benefit streams could be created.

Related quantitative researches, for example, Hofmann [31], studied the impacts of volume, variety, and velocity properties on the supply chain bullwhip effect, and results indicated that the Big Data's "velocity" character had the biggest influences on the bullwhip effect. Tan et al. [32] proposed a data analytics method to help companies obtain the potential of innovation and get competitive advantages.

Overall, few studies analyze the changes of the supply chain structure in a Big Data environment and use a mathematical model to analyze the decision-making and coordination problems of the supply chain investment on obtaining BDI. The purpose of this paper is to compensate for the lack.

2.4. Supply Chain Collaboration. In 2004, Boyaci and Gallego [33] used a game-theoretic method for modeling a supply chain competition, and their resulting model indicated that supply chain coordination was an equilibrium strategy but not one firm that added supply chain revenues. Therefore, the issue of supply chain coordination is becoming more and more important. A vital study to solve this issue is to design coordination contracts.

In general, coordination contracts have many versions, for example, buy back contract [34], quantity discount contract [35-37], and revenue sharing contract [38]. Among them, quantity discount contract and revenue sharing contract were widely used and discussed. For example, based on the stock-dependent phenomenon, Parthasarathi et al. [39] studied the role of the quantity discount and the return policy in the coordination of a supply chain; based on the stockprice dependent demand, Panda [40] discussed influences of revenue and cost sharing contracts; Yang et al. [41] researched the influence of the credit period and quantity discount to coordinate a two-echelon supply chain.

Based on the easy-to-use feature of the quantity discount contract, in this paper, we will discuss whether the quantity discount contract can make the supply chain coordination in a Big Data environment.

\section{Development of Supply Chain Model in a Big Data Environment}

In a Big Data environment, a data services company should be included in the supply chain. Here, we call this an information services company (ISC). To provide effective personalized service and ensure the dynamic combination and flexibility of the production line, the central enterprise (CE) must allocate a number of tasks to scattered manufacturers (SM) $[17,32]$. CE is responsible for dispatching materials, obtaining information, and completing the final product to deploying
SM. Therefore, under the Big Data era, the development of the traditional supply chain with one manufacturer and one retailer is shown in Figure 1. In Figure 1, goods services stand for sale and transportation production and so on. Information services express that ISC can provide the services of data rental, sales, analysis, and so on. Obtaining data expresses that an organization can obtain data of others during the data transaction process. By processing these data they can get the related information.

\section{Model Description}

In a Big Data environment, considering consumers' heterogeneity on production and the trust degree on the related production information, an analysis will be implemented to help stakeholders explore the potential benefit space. Therefore, in this paper, a monopoly environment is structured to characterize the investment decision-making rule and the coordination contract of stakeholders.

\subsection{Variables and Parameters}

$\alpha, \delta$ are discount factor of the value. $\alpha$ is affected by consumers' heterogeneity on production, and $\delta$ is impacted by consumers' trust on the production information from the third party.

$c_{s}$ stands for the marginal cost to make a product.

$c_{v}$ is the inventory cost of CE.

$c_{r}, c_{d}$ are the sales cost of retailer $\left(c_{r}\right)$ and CE $\left(c_{d}\right)$.

$c_{i}, c_{o}$ are the acquisition costs of consumer BDI $\left(c_{i}\right)$ and the internal BDI of CE $\left(c_{o}\right)$.

$p^{y}$ is the retail price under $y$ model: $y=\{\mathrm{NBD}, \mathrm{BD}$, NDC, DC, Z . NBD model is defined as the benefit model of the decentralized supply chain under the condition of no acquiring BDI. BD model is the benefit model of the decentralized supply chain under the condition of acquiring BDI. NDC stands for the benefit model of the centralized supply chain under the condition of no acquiring BDI. DC expresses the benefit model of the centralized supply chain under the condition of acquiring BDI. $Z$ presents the benefit model after coordination.

$Q^{y}$ is the sales volume under $y$ model; in this paper, we assume that it is equal to the size of the potential market.

$\pi_{f}^{y}$ is the revenues under $y$ model. $f=\{d, r\}, d$ represents $\mathrm{CE}$, and $r$ stands for $\mathrm{OR}$.

$w^{y}$ is the wholesale price under $y$ model.

$\vartheta$ is the industry cost improvement coefficient, through analyzing the internal BDI of an enterprise, and then it is used in the enterprise to reduce the enterprise's cost. For example, $c_{s}$ can be improved to $\vartheta c_{s}$. And $\vartheta \in[0,1]$. 


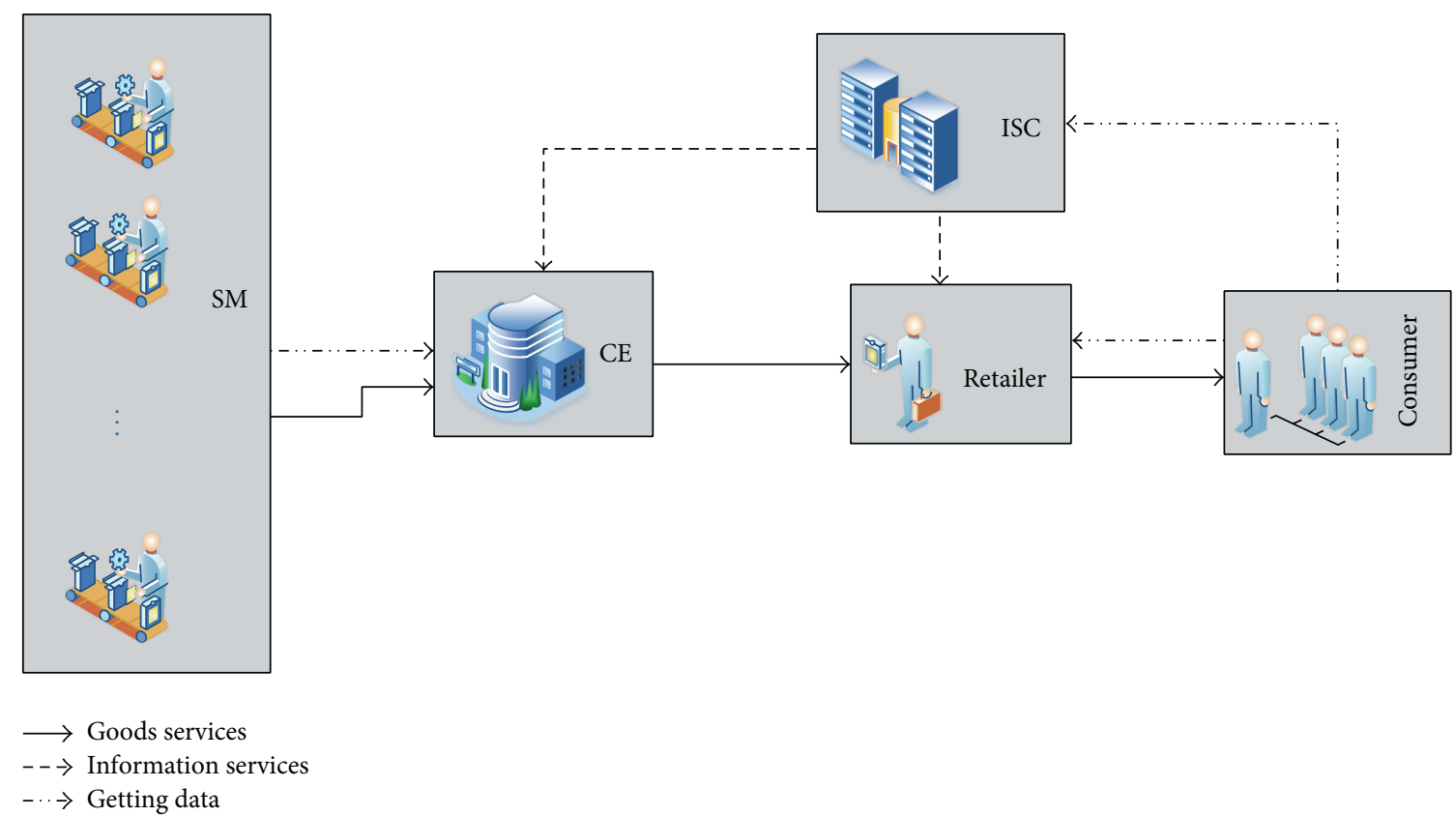

Figure 1: Model of the supply chain in a Big Data environment.

\subsection{Demand Function and Model Assumptions}

4.2.1. Demand Function. In what follows, relationships between the self-selection quantities and the retail price are presented. Suppose that there is one retailer and one CE in the supply chain, and the retailer sells the production online. The utility that a consumer of type $v$ enjoys as purchase of the commodity is $U=\delta \alpha v-p^{y}$; here, $v \in[0,1]$. And the demand function can be described as follows.

(1) If $v>p^{y} / \delta \alpha$, the demand function is

$$
Q^{y}=1-\frac{p^{y}}{\delta \alpha} \text {. }
$$

(2) If $v \leq p^{y} / \delta \alpha$, the demand function is

$$
Q^{y}=0 \text {. }
$$

The second situation is pointless; therefore, we only discuss the first case.

\subsection{Model Assumptions}

(i) The supply chain is composed of a plurality of SM, one $\mathrm{CE}$, one ISC, one retailer, and end consumers.

(ii) Using Big Data information optimizes the production process; therefore, we assume that the optimization coefficient of the production cost is $\vartheta$ consistently and that it is not affected by the handler. Therefore, the product cost can be optimized and become $\vartheta c_{s}$. The sales cost of CE is $\vartheta c_{d}$, and the sales cost of the retailer is $\vartheta c_{r}$, and the inventory cost of CE can be improved to $\vartheta c_{v}$. (iii) There are two methods to obtain BDI: one is from ISC, and the other is from information source. Because the two methods have advantages and disadvantages, we assume that the sum of the cost of obtaining consumer information is $c_{o}$, regardless of which methods are adopted. Assume that the cost of CE spending on obtaining themselves internal information is $c_{i}$.

(iv) BDI of the supply chain does not result in leakage risk. Members in the supply chain own the same information and are risk neutral.

\section{Investment Decision-Making of Gaining BDI}

5.1. The Decentralized Supply Chain. In order to form a contrast, we established the benefit model under the condition of no acquiring BDI and called it NBD model. Then we built the revenue model under the condition of acquiring BDI and called it BD model. Finally, we compared their optimal benefits.

5.1.1. NBD Model. In the NBD model, the benefit functions of $\mathrm{CE}$ and the retailer were

$$
\begin{aligned}
& \pi_{d}^{\mathrm{NBD}}=\left(w^{\mathrm{NBD}}-c_{s}-c_{d}-c_{v}\right) Q^{\mathrm{NBD}}, \\
& \pi_{r}^{\mathrm{NBD}}=\left(p^{\mathrm{NBD}}-w^{\mathrm{NBD}}-c_{r}\right) Q^{\mathrm{NBD}} .
\end{aligned}
$$

Here, the function of the market demand was

$$
Q^{\mathrm{NBD}}=1-\frac{p^{\mathrm{NBD}}}{\delta \alpha} .
$$


Based on the backward-induction method, we got

$$
\begin{gathered}
\left(p^{\mathrm{NBD} *}, w^{\mathrm{NBD} *}, \mathrm{Q}^{\mathrm{NBD} *}\right)=\left(\frac{\left(c_{d}+c_{r}+c_{s}+c_{v}+3 \alpha \delta\right)}{4},\right. \\
\left.\frac{\left(c_{d}-c_{r}+c_{s}+c_{v}+\alpha \delta\right)}{2}, \frac{\left(\alpha \delta-c_{d}-c_{r}-c_{s}-c_{v}\right)}{4 \alpha \delta}\right) .
\end{gathered}
$$

Based on (5), the benefit functions of CE and the retailer would be

$$
\begin{aligned}
& \pi_{d}^{\mathrm{NBD} *}=\frac{\left(\alpha \delta-c_{d}-c_{r}-c_{s}-c_{v}\right)^{2}}{8 \alpha \delta}, \\
& \pi_{r}^{\mathrm{NBD} *}=\frac{\left(\alpha \delta-c_{d}-c_{r}-c_{s}-c_{v}\right)^{2}}{16 \alpha \delta} .
\end{aligned}
$$

Theorem 1. In the NBD model, $\left(p^{N B D *}, w^{N B D *}, Q^{N B D *}\right)$ is the game equilibrium solution of the supply chain members. $\left(\pi_{d}^{N B D *}, \pi_{r}^{N B D *}\right)$ is the optimal benefits of CE and the retailer, respectively.

For the decentralized supply chain, only when the supply chain members obtain a positive benefit can the supply chain remain stable. In order to avoid supply chain interruption, $\mathrm{Q}^{N B D *}>0$ must be met. Therefore, we got

$$
\alpha \delta>c_{d}+c_{r}+c_{s}+c_{v} .
$$

5.1.2. BD Model. In the BD model, the benefit functions of $\mathrm{CE}$ and the retailer were

$$
\begin{aligned}
& \pi_{d}^{\mathrm{BD}}=\left(w^{\mathrm{BD}}-\vartheta c_{s}-\vartheta c_{d}-\vartheta c_{v}-c_{o}-c_{i}\right) Q^{\mathrm{BD}}, \\
& \pi_{r}^{\mathrm{BD}}=\left(p^{\mathrm{BD}}-w^{\mathrm{BD}}-c_{i}-\vartheta c_{r}\right) Q^{\mathrm{BD}} .
\end{aligned}
$$

Here, the function of the market demand was

$$
Q^{\mathrm{BD}}=1-\frac{p^{\mathrm{BD}}}{\delta \alpha} .
$$

Through resolving, we got

$$
\begin{aligned}
& \left(p^{\mathrm{BD} *}, w^{\mathrm{BD} *}, Q^{\mathrm{BD} *}\right) \\
& =\left(\frac{\left(2 c_{i}+c_{o}+\vartheta c_{d}+\vartheta c_{r}+\vartheta c_{s}+\vartheta c_{v}+3 \alpha \delta\right)}{4},\right. \\
& \quad \frac{\left(c_{o}+\vartheta c_{d}-\vartheta c_{r}+\vartheta c_{s}+\vartheta c_{v}+\alpha \delta\right)}{2}, \\
& \left.\quad \frac{\left(\alpha \delta-2 c_{i}-c_{o}-\vartheta c_{d}-\vartheta c_{r}-\vartheta c_{s}-\vartheta c_{v}\right)}{4 \alpha \delta}\right) .
\end{aligned}
$$

Based on (11), the benefit functions of CE and the retailer would be

$$
\begin{aligned}
& \pi_{d}^{\mathrm{BD} *}=\frac{\left(\alpha \delta-2 c_{i}-c_{o}-\vartheta c_{d}-\vartheta c_{r}-\vartheta c_{s}-\vartheta c_{v}\right)^{2}}{8 \alpha \delta}, \\
& \pi_{r}^{\mathrm{BD} *}=\frac{\left(\alpha \delta-2 c_{i}-c_{o}-\vartheta c_{d}-\vartheta c_{r}-\vartheta c_{s}-\vartheta c_{v}\right)^{2}}{16 \alpha \delta} .
\end{aligned}
$$

Theorem 2. Under BD model, $\left(p^{B D *}, w^{B D *}, Q^{B D *}\right)$ is the game equilibrium solution of the supply chain members. $\left(\pi_{d}^{B D *}, \pi_{r}^{B D *}\right)$ is the optimal benefits of $C E$ and the retailer, respectively.

For the decentralized supply chain, only when the supply chain members obtain a positive benefit can the supply chain remain stable. In order to avoid the supply chain interruption, $\mathrm{Q}^{B D *}>0$ must be met. Therefore, we got

$$
2 c_{i}+c_{o}<\alpha \delta-\vartheta\left(c_{d}+c_{r}+c_{s}+c_{v}\right)
$$

Conclusion 1. When (14) can be met, supply chain members will use BDI to optimize enterprise costs; otherwise, they will not spend money on getting BDI.

5.1.3. Investment Decision of BDI under the Decentralized Decision-Making. In the Big Data era, most organizations want to use BDI to help them gain more competitive advantages, so it is an urgent problem for enterprises to analyze the investment condition of BDI.

In this section, based on the above models, the comparison analysis about the optimal revenues would be given. Assume that $\Delta \pi_{x}(x=1,2)$ expressed the profit differences. $\Delta \pi_{1}=\pi_{d}^{\mathrm{BD} *}-\pi_{d}^{\mathrm{NBD} *}>0$, and based on (6) and (12), we got $2 c_{i}+c_{o}<(1-\vartheta)\left(c_{d}+c_{r}+c_{s}+c_{v}\right)$. It expressed that when $2 c_{i}+c_{o}<(1-\vartheta)\left(c_{d}+c_{r}+c_{s}+c_{v}\right)$ could be met, $\mathrm{CE}$ would get more benefits by using BDI to make decision. $\Delta \pi_{2}=\pi_{r}^{\mathrm{BD} *}-\pi_{r}^{\mathrm{NBD} *}>0$, and based on (8) and (14), we got that $2 c_{i}+c_{o}<(1-\vartheta)\left(c_{d}+c_{r}+c_{s}+c_{v}\right)$. It presented that when $2 c_{i}+c_{o}<(1-\vartheta)\left(c_{d}+c_{r}+c_{s}+c_{v}\right)$, the retailer would get more benefits by using BDI to make decision. Therefore, we got Conclusion 2.

Conclusion 2. When $2 c_{i}+c_{o}<(1-\vartheta)\left(c_{d}+c_{r}+c_{s}+c_{v}\right)$, it is suitable for the $\mathrm{CE}$ and the retailer to invest in BDI. Meanwhile, the cost thresholds that the $\mathrm{CE}$ and retailer can spend on obtaining BDI are same.

5.2. The Centralized Supply Chain. In the centralized decision-making, firstly, we established the benefit models under the condition of no acquiring BDI and called it NDC model. Then, we built the revenue models under the condition of acquiring BDI and called it DC model. Finally, we compared the optimal benefits of the two models.

5.2.1. NDC Model. In the NDC model, the benefit function of the centralized supply chain was

$$
\pi_{j}^{\mathrm{NDC}}=\left(p^{\mathrm{NDC}}-c_{r}-c_{s}-c_{d}-c_{v}\right) Q^{\mathrm{NDC}}
$$

Here, the function of the market demand was

$$
Q^{\mathrm{NDC}}=1-\frac{p^{\mathrm{NDC}}}{\delta \alpha}
$$


Based on (15) and (16), we got

$$
\begin{aligned}
& \left(p^{\mathrm{NDC} *}, \mathrm{Q}^{\mathrm{NDC} *}\right)=\left(\frac{\left(c_{d}+c_{r}+c_{s}+c_{v}+\delta \alpha\right)}{2},\right. \\
& \left.\quad \frac{\left(\delta \alpha-c_{d}-c_{r}-c_{s}-c_{v}\right)}{2 \delta \alpha}\right) .
\end{aligned}
$$

Based on (17), we got

$$
\pi_{j}^{\mathrm{NDC} *}=\frac{\left(\delta \alpha-c_{d}-c_{r}-c_{s}-c_{v}\right)^{2}}{4 \delta \alpha} .
$$

Theorem 3. $\left(p^{N D C *}, Q^{N D C *}\right)$ is the game equilibrium solution of the supply chain members in the NDC model. $\pi_{j}^{N D C *}$ is the optimal benefit of the centralized supply chain.

For the centralized supply chain, only when the supply chain members obtain a positive benefit can the supply chain remain stable. In order to avoid the supply chain interruption, $Q^{N D C}>$ 0 must be met. Therefore, we got

$$
\delta \alpha>c_{d}+c_{r}+c_{s}+c_{v}
$$

5.2.2. DC Model. In the DC model, the benefit function of the centralized supply chain was

$$
\pi_{j}^{\mathrm{DC}}=\left(p^{\mathrm{DC}}-2 c_{i}-c_{o}-\vartheta c_{s}-\vartheta c_{r}-\vartheta c_{d}-\vartheta c_{v}\right) Q^{\mathrm{DC}} .
$$

Here, the function of the market demand was

$$
Q^{\mathrm{DC}}=1-\frac{p^{\mathrm{DC}}}{\delta \alpha} .
$$

Based on formulas (20) and (21), we got

$$
\begin{aligned}
& \left(p^{\mathrm{DC} *}, Q^{\mathrm{DC} *}\right) \\
& =\left(\frac{\left(2 c_{i}+c_{o}+\delta \alpha+\vartheta c_{s}+\vartheta c_{r}+\vartheta c_{d}+\vartheta c_{v}\right)}{2},\right. \\
& \left.\frac{\left(\delta \alpha-2 c_{i}-c_{o}-\vartheta c_{s}-\vartheta c_{r}-\vartheta c_{d}-\vartheta c_{v}\right)}{2 \delta \alpha}\right) .
\end{aligned}
$$

Based on (22), we got

$$
\pi_{j}^{\mathrm{DC} *}=\frac{\left(\delta \alpha-2 c_{i}-c_{o}-\vartheta c_{s}-\vartheta c_{r}-\vartheta c_{d}-\vartheta c_{v}\right)^{2}}{4 \delta \alpha} .
$$

Theorem 4. $\left(p^{D C *}, Q^{D C *}\right)$ is the game equilibrium solution of the supply chain members in the DC model. $\pi_{j}^{D C *}$ is the optimal benefit of the centralized supply chain.

For the centralized supply chain, only when the supply chain members obtain a positive benefit can the supply chain remain stable. In order to avoid the supply chain interruption, $Q^{D C}>0$ must be met. Therefore, we got

$$
2 c_{i}+c_{o}<\alpha \delta-\vartheta\left(c_{d}+c_{r}+c_{s}+c_{v}\right) .
$$

Conclusion 3. When (24) can be met, supply chain members will use BDI to optimize their costs; otherwise, they will not spend money on obtaining BDI.
5.2.3. Investment Decision of BDI in the Centralized DecisionMaking. In this section, the comparison analysis of the optimal revenues in the NDC and DC models would be given. Assume that $\Delta \pi_{j}$ expressed the profit differences between $\pi_{j}^{\mathrm{DC} *}$ and $\pi_{j}^{\mathrm{NDC} *}$. Also $\Delta \pi_{j}=\pi_{j}^{\mathrm{DC} *}-\pi_{j}^{\mathrm{NDC} *}=M N / 2 \alpha \delta>0$, here, $M=2 c_{i}+c_{o}-(1-\vartheta)\left(c_{d}+c_{r}+c_{s}+c_{v}\right), N=2 c_{i}+c_{o}+$ $(1+\vartheta)\left(c_{d}+c_{r}+c_{s}-c_{v}\right)-2 \alpha \delta$. Through analyzing, we got $2 c_{i}+c_{o}<(1-\vartheta)\left(c_{d}+c_{r}+c_{s}+c_{v}\right)$. Combining with Conclusion 3 we got Conclusion 4 .

Conclusion 4. When $2 c_{i}+c_{o}<(1-\vartheta)\left(c_{d}+c_{r}+c_{s}+c_{v}\right)$, it is suitable for the centralized supply chain to invest in BDI. Meanwhile, the cost thresholds that the centralized supply chain members can spend on obtaining BDI are same as the decentralized supply chain.

Based on Conclusion 4, we could find Conclusion 5.

Conclusion 5. The acquisition costs of BDI (i.e., $2 c_{i}+c_{o}$ ) have a positive relationship with the costs (i.e., $c_{d}+c_{r}+c_{s}+c_{v}$ ) needed to be improved and a negative relationship with the cost improvement coefficient (i.e., 9 ).

5.3. Coordination Analysis of the Decentralized Supply Chain. Comparing formulas (11) and (22), in the BD and DC models, the centralized supply chain had a higher sales volume than the decentralized supply chain. It was true that the optimal benefit of the centralized supply chain was big compared with the decentralized supply chain. Meanwhile, the centralized supply chain had a cheaper retail price than the decentralized supply chain; therefore, the decentralized supply chain had a "double marginalized effect." The sales volume of the supply chain was not optimal, so the profits of the decentralized supply chain had space to be improved. Contracts could be used to make it coordinate.

The quantity discount contract was used to coordinate the supply chain. CE offered the quantity discount contract $w^{Z}$, which might maximize the profit of the supply chain. $w^{Z}$ was the wholesale price after discounting, and it was equal to $w_{0}-\rho Q^{z}$, and $w_{0}$ was the highest wholesale price. $\rho$ stood for the discount coefficient; it was related to the retailer's order quantity $Q^{z}$ (here, assume that the order quantity of products and the sales volume are equal). Therefore, the profits of CE and retailer were

$$
\begin{aligned}
& \pi_{d}^{Z}=\left(w_{0}-\rho Q^{z}-\vartheta c_{s}-c_{o}-c_{i}-\vartheta c_{d}-\vartheta c_{v}\right) Q^{z}, \\
& \pi_{r}^{Z}=\left(p^{Z}-w_{0}+\rho Q^{z}-c_{i}-\vartheta c_{r}\right) Q^{z} .
\end{aligned}
$$

Here, the function of market demand was

$$
Q^{z}=1-\frac{p^{Z}}{\delta \alpha}
$$

Through calculating, we got

$$
Q^{z *}=\frac{\left(c_{i}+w_{0}-\delta \alpha+\vartheta c_{r}\right)}{2(\rho-\delta \alpha)} .
$$

According to the coordination thought of supply chain, we got Conclusion 6. 
Conclusion 6. If the decentralized supply chain spends money on obtaining BDI, moreover, $w_{0}=\left(\delta \alpha-c_{i}-\vartheta c_{r}\right)-$ $(\rho-\alpha \delta)\left(2 c_{i}+c_{o}-\alpha \delta+\vartheta c_{d}+\vartheta c_{r}+\vartheta c_{s}+\vartheta c_{v}\right) / \alpha \delta$ and $\alpha \delta / 2 \leq$ $\rho \leq 3 \alpha \delta / 4$, the supply chain can be coordinated perfectly.

Proof. Under the condition of using BDI, In order to make the decentralized supply chain achieve the same benefits with the centralized supply chain, $Q^{z *}=\left(\alpha \delta-2 c_{i}-c_{o}-c_{d}-c_{r}-c_{s}-\right.$ $\left.c_{v}\right) / 4 \alpha \delta$ should be met. We got $w_{0}=\left(\delta \alpha-c_{i}-\vartheta c_{r}\right)-(\rho-$ $\alpha \delta)\left(2 c_{i}+c_{o}-\alpha \delta+\vartheta c_{d}+\vartheta c_{r}+\vartheta c_{s}+\vartheta c_{v}\right) / \alpha \delta$. Consider

$$
\begin{aligned}
& \pi_{d}^{Z *}=\frac{\rho\left(2 c_{i}+c_{o}-\alpha \delta+\vartheta c_{d}+\vartheta c_{r}+\vartheta c_{s}+\vartheta c_{v}\right)^{2}}{\left(4 \alpha^{2} \delta^{2}\right)}, \\
& \pi_{r}^{Z *} \\
& =\frac{(\alpha \delta-\rho)\left(2 c_{i}+c_{o}-\alpha \delta+\vartheta c_{d}+\vartheta c_{r}+\vartheta c_{s}+\vartheta c_{v}\right)^{2}}{\left(4 \alpha^{2} \delta^{2}\right)} .
\end{aligned}
$$

In order to meet the conditions of the supply chain coordination, $\pi_{d}^{Z *} \geq \pi_{d}^{\mathrm{BD} *}$ and $\pi_{r}^{Z *} \geq \pi_{r}^{\mathrm{BD} *}$ should be met. Therefore, Conclusion 6 was confirmed.

\section{Numerical Examples}

In order to test the validity of the above conclusions and investigate the effects of cost parameters change on supply chain investment and coordination, a numerical simulation analysis method was used. From [42], let $\vartheta=0.65$. Through a week research in a car company of Chongqing, China, we set $c_{d}=0.03, c_{r}=0.05, c_{s}=0.95$, and $c_{v}=0.02$. Based on (8), we got $\delta \alpha>0.15$, and without loss of generality, we set $\alpha=0.9$ and $\delta=0.8$.

Based on Theorems 1 and 3 , we got $\left(\pi_{d}^{\mathrm{NBD} *}, \pi_{r}^{\mathrm{NBD} *}\right.$, $\left.\pi_{j}^{\mathrm{NDC} *}\right)=(0.056,0.028,0.113)$. Based on Conclusion 4 , we got $2 c_{i}+c_{o}<0.053$. Without loss of generality, we set $2 c_{i}+c_{o}=0.02,\left(\pi_{d}^{\mathrm{BD} *}, \pi_{r}^{\mathrm{BD} *}, \pi_{j}^{\mathrm{DC} *}\right)=(0.062,0.032,0.126)$. According to analyze, we found $\Delta \pi_{d}^{\mathrm{BD}}=\pi_{d}^{\mathrm{BD} *}-\pi_{d}^{\mathrm{NBD} *}>0$, $\Delta \pi_{r}^{\mathrm{BD}}=\pi_{r}^{\mathrm{BD} *}-\pi_{r}^{\mathrm{NBD} *}>0, \pi_{j}^{\mathrm{DC} *}>\pi_{j}^{\mathrm{NDC} *}$, and the related conclusions were verified. Effects of the BDI acquisition costs (i.e., $2 c_{i}+c_{o}$ ) on the incremental benefits of the decentralized supply chain were shown in Figure 2 . The $x$-axis represents the acquisition cost of BDI $\left(2 c_{i}+c_{o}\right)$, and the $y$-axis indicates the incremental benefits of the decentralized supply chain $(\Delta \pi)$.

From Figure 2 we could get that when the acquisition costs of BDI were within a certain range, the supply chain using BDI had a higher revenue than the supply chain without adopting BDI. The acquisition costs threshold was related to the cost improvement coefficient $(\vartheta)$ and the costs needed to improve $\left(c_{d}+c_{r}+c_{s}+c_{v}\right)$, and the relationships were shown in Figure 3. Based on Figure 3(a), we could get that the acquisition costs threshold $\left(2 c_{i}+c_{o}\right)$ was getting smaller and smaller with the increase of the cost improvement coefficient

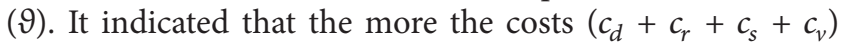
reduced, the bigger the acquisition costs threshold $\left(2 c_{i}+c_{o}\right)$ would be. From Figure 3(b), we found that the acquisition costs threshold $\left(2 c_{i}+c_{o}\right)$ would increase with the rise of the

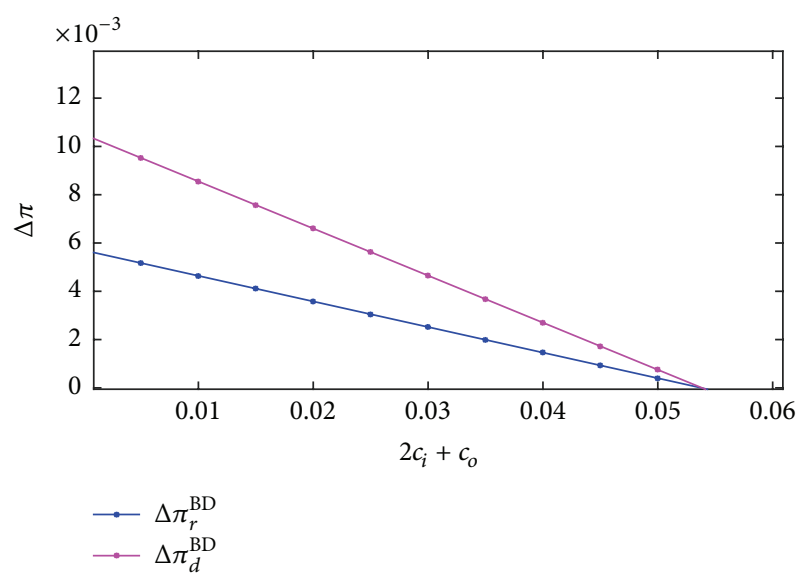

Figure 2: Effects of the BDI acquisition costs on benefits of the decentralized supply chain members.

costs $\left(c_{d}+c_{r}+c_{s}+c_{v}\right)$. It demonstrated that the bigger the costs $\left(c_{d}+c_{r}+c_{s}+c_{v}\right)$, the bigger the acquisition costs threshold $\left(2 c_{i}+c_{o}\right)$. Conclusion 5 was proved.

Due to $\pi_{d}^{\mathrm{BD} *}+\pi_{r}^{\mathrm{BD} *}=0.094$ and $\pi_{j}^{\mathrm{DC} *}=0.126$, thus, $\pi_{d}^{\mathrm{BD} *}+\pi_{r}^{\mathrm{BD} *}<\pi_{j}^{\mathrm{DC} *}$. Meanwhile, $\left(p^{\mathrm{BD} *}, p^{\mathrm{DC} *}\right)=(0.659$, $0.417)$, and we could find $p^{\mathrm{DC} *}<p^{\mathrm{BD} *}$. In addition, $\left(Q^{\mathrm{BD} *}\right.$, $\left.Q^{D C *}\right)=(0.209,0.418)$; therefore, $Q^{D C *}>Q^{B D *}$. It indicated that the centralized supply chain had a higher sales volume and profit than the decentralized supply chain.

Therefore, after using BDI, the decentralized supply chain appeared as a "double marginalized effect." In order to eliminate the effect, the wholesale price $w_{0}=0.094+0.836 \rho$ was given. In order to achieve the coordination conditions of the supply chain, we set the incremental benefits of $\mathrm{CE}$ and the retailer benefit as $\Delta \pi_{d}^{Z}$ and $\Delta \pi_{r}^{Z}$, respectively. Here, $\Delta \pi_{d}^{Z}=\pi_{d}^{Z *}-\pi_{d}^{\mathrm{BD} *}$ and $\Delta \pi_{r}^{Z}=\pi_{r}^{Z *}-\pi_{r}^{\mathrm{BD} *}$. Through analyzing, we got the relationship between $\Delta \pi_{y}^{Z}$ and the coordinating parameters (i.e., $\rho$ ), as shown in Figure 4. The $x$-axis represents the discount coefficient, and the $y$ axis expresses the incremental benefits of the supply chain members after coordination.

Based on Figure 4, we could get that $\Delta \pi_{d}^{Z}$ would increase with the increase of $\rho$, and $\Delta \pi_{r}^{Z}$ would reduce with the increase of $\rho$. In this figure, $R$ represented the range of parameter $\rho$, and the range could make the supply chain coordinate. Without loss of generality, we set $\rho=0.4$, there were $\left(\pi_{d}^{Z *}, \pi_{r}^{Z *}\right)=(0.07,0.056)$, and we could find $\pi_{d}^{Z *}+\pi_{r}^{Z *}=$ $\pi_{j}^{\mathrm{DC} *}$. In addition, $\pi_{d}^{Z *}>\pi_{d}^{\mathrm{BD} *}$, and $\pi_{r}^{Z *}>\pi_{r}^{\mathrm{BD} *}$. Thus, under the quantity discount contract, the decentralized supply chain had an equal benefit with the centralized supply chain after coordination. Conclusion 6 was confirmed.

\section{Conclusions and Significances}

7.1. Conclusions. In a Big Data environment, by analyzing the importance of a Data Company in the supply chain, the original model of the supply chain was constructed. Then, considering consumers' preference and the trust on 


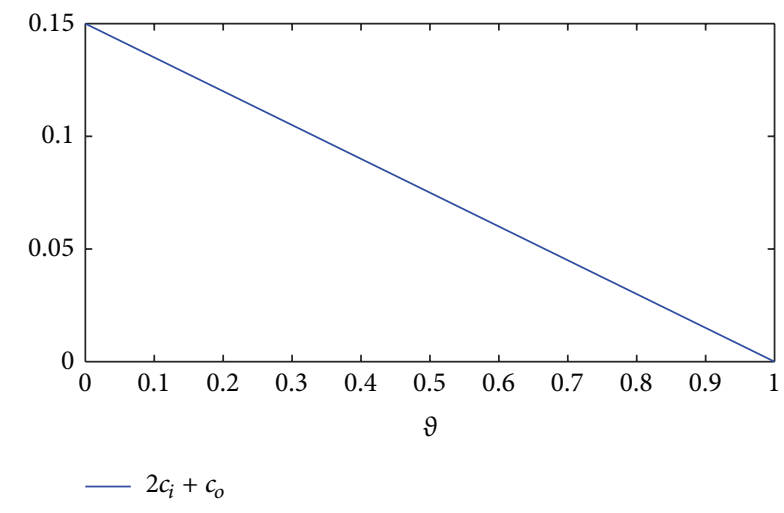

(a)

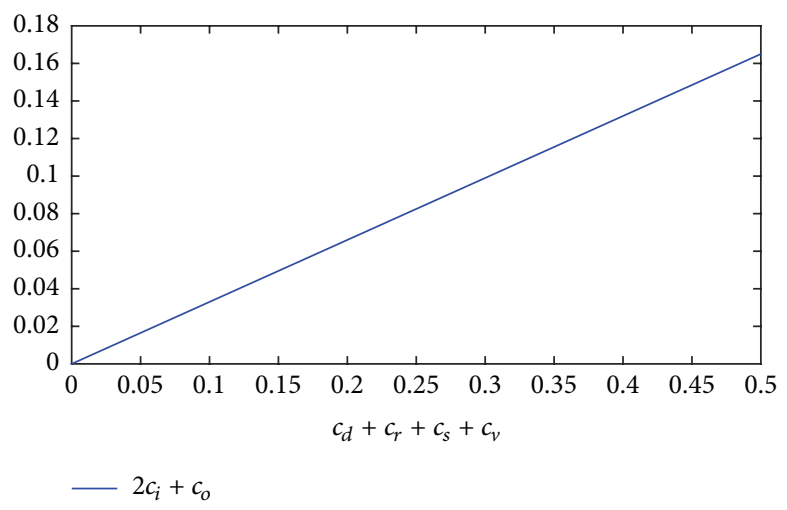

(b)

FIGURE 3: Effects of the cost and its improvement coefficient on the acquisition costs threshold.

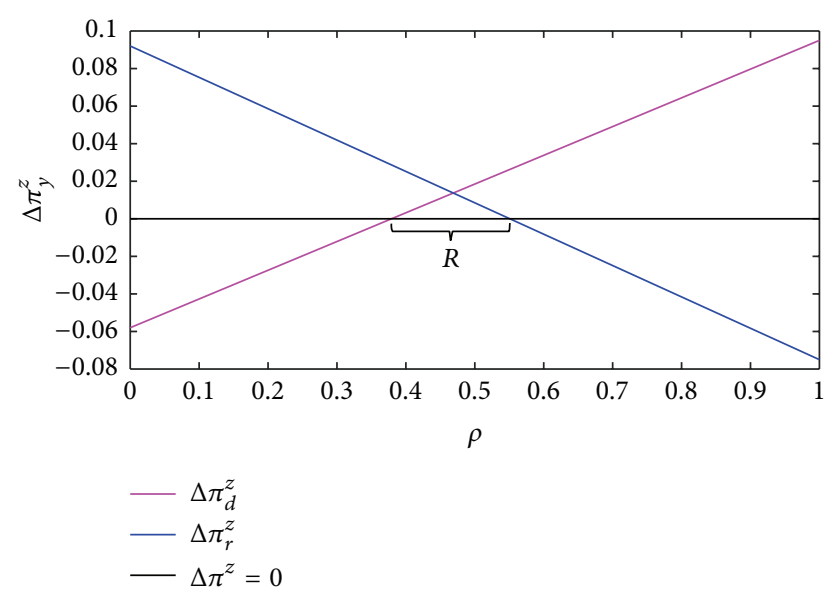

FIGURE 4: Effects of contract parameter on benefits of supply chain members.

the evaluation from the third party, the demand and benefit model was constructed. By analyzing these models we found the following.

(1) Under the condition of obtaining and using BDI, the more the costs $\left(c_{d}+c_{r}+c_{s}+c_{v}\right)$ needed to be improved, the bigger the acquisition costs threshold $\left(2 c_{i}+c_{o}\right)$.

Namely, whether the enterprises using BDI to improve their costs would gain more benefits or not was determined by the improvement space of their enterprises costs. Therefore, for enterprises that wanted to use BDI to improve their costs, they had one way to offset the acquisition costs of BDI; it was to excavate the value of Big Data fully and thereby use it to improve their costs.

(2) The acquisition costs thresholds of the decentralized supply chain and the centralized supply chain were equal.

These results suggested that whether the supply chain was the decentralized decision-making and the centralized decision-making, if its members used BDI to improve their costs, the acquisition costs thresholds of BDI were equal.
Moreover, the maximum value that they could undertake was same.

(3) For the decentralized supply chain, if it had used BDI to improve their costs, it would result in a "double marginalized effect," and the quantity discount contract could make it coordinate. Moreover, the contract could achieve a win-win outcome for both $\mathrm{CE}$ and the retailer.

(4) Meanwhile, the threshold of the discount coefficient was got, and it was related to the discount factor of value $(\alpha, \delta)$.

These results showed that the quantity discount contract could achieve the coordination of the decentralized supply chain. However, the discount coefficient should meet a certain range; the range was determined by consumer preference and the trust on the evaluation from the third party. Therefore, in a Big Data environment, consumer behavior analysis was important.

7.2. Practical Significance. In the Big Data era, BDI will gradually become important, based on the characteristics of Big Data, and a Data Company in the supply chain is getting more and more important. Enterprises may pay more attention to gain Big Data service from a Data Company, which may cause the change of supply chain structure and lead to the new problem of supply chain investment decisionmaking and coordination. And the investment cost threshold is closely related to the enterprise cost improvement coefficient, and the threshold of the discount coefficient is related to the discount factor of value. This finding is important for enterprise to implement the Big Data plan. Next, we will give some advices for enterprise to guide their Big Data plan.

(1) For the complex products whose production cost is high and new products whose sales cost is high, if enterprises analyze and use BDI to improve their costs, this may help them gain more benefits. However, if the benefits cannot offset the acquisition costs of BDI, namely, the threshold of acquisition costs on $\mathrm{BDI}$ is bigger than the improved costs, under this 
situation, enterprise can adopt two methods to adjust and control this situation: one is to excavate the value of Big Data fully to reduce the cost improvement coefficient and increase the improved costs (i.e., increasing the value of $\left.(1-\vartheta)\left(c_{d}+c_{r}+c_{s}+c_{v}\right)\right)$; another is to reduce the acquisition costs of $\mathrm{BDI}$ through coordination or other ways.

(2) Under the decentralized decision-making, for enterprises that had used BDI to improve their costs, if they want to gain more benefits, the quantity discount contract can help them. Moreover, this contract can enhance the overall revenues of the supply chain. What the enterprise need to do is to set a suitable discount coefficient, and it is related to consumer preference and the trust on the evaluation from the third party, and in a Big Data environment, these pieces of information can be forecasted based on consumers' BDI.

7.3. Theoretical Significance. In a Big Data environment, BDI is becoming increasingly important, based on the characteristics of Big Data, and a Data Company in the supply chain is getting more and more important. This might lead to the change of the supply chain structure; thus, we proposed the original model of a two-stage supply chain in a Big Data environment, which made up for the lack of supply chain structure under Big Data era.

Based on the original model and the utility theory of value, through analyzing some changes of consumer behavior in a Big Data environment, the market demand function was got. Then, analyzing and using BDI to improve enterprise's costs (i.e., sales costs, production costs, and inventory cost) was considered. Then the benefits model of stakeholders was built. By analyzing, the acquisition costs thresholds of BDI were got under the decentralized decision-making and the centralized decision-making. They were equal under the two decision-making models. These findings compensated for the weaknesses of the supply chain investment decision-making in a Big Data environment.

Meanwhile, we proved that the quantity discount contract could be used and made the supply chain coordinate, and the threshold of the discount coefficient was got, and it was related to the changes of consumer behavior (i.e., consumer preferences and the trust on the evaluation from the third party). These findings enriched the use environment of the quantity discount contract and made up for the research shortages of the supply chain coordination under the new environment.

\section{Future Research}

In this paper, we considered only one form of the supply chain. Next, the extended forms of the supply chain should be considered. For example, we can research the problems of the investment decision-making and coordination based on a double-channel supply chain, a multichannel supply chain, or a closed-loop supply chain. In addition, we used only the quantity discount contract to coordinate the supply chain. In the next step, we should discuss and compare the effects of the different contracts on the supply chain coordination and revenue in a Big Data environment.

\begin{tabular}{|c|c|}
\hline \multicolumn{2}{|c|}{ Abbreviations } \\
\hline CE: & Central enterprise \\
\hline ISC: & Information services company \\
\hline SM: & Scattered manufacturers \\
\hline BDI: & Big Data information \\
\hline NBD model: & $\begin{array}{l}\text { Benefit models of the decentralized } \\
\text { supply chain under the condition of } \\
\text { no acquiring BDI }\end{array}$ \\
\hline $\mathrm{BD}:$ & $\begin{array}{l}\text { Benefit models of the decentralized } \\
\text { supply chain under the condition of } \\
\text { acquiring BDI }\end{array}$ \\
\hline NDC: & $\begin{array}{l}\text { Benefit models of the centralized } \\
\text { supply chain under the condition of } \\
\text { no acquiring BDI }\end{array}$ \\
\hline DC: & $\begin{array}{l}\text { Benefit models of the centralized } \\
\text { supply chain under the condition of } \\
\text { acquiring BDI. }\end{array}$ \\
\hline
\end{tabular}

\section{Competing Interests}

The authors declare that there are no competing interests.

\section{Authors' Contributions}

Pan Liu and Shu-ping Yi conceived and designed the experiments and performed the experiments; Pan Liu analyzed the data and wrote the paper.

\section{References}

[1] J. Gantz and D. Reinsel, "Extracting value from chaos," Idcemc2 Report, 2011.

[2] H. X. Z. Huixin, "Build enterprise competitive intelligence system model based on big data," Journal of Intelligence, vol. 32, no. 3, pp. 37-43, 2013.

[3] M. A. Andrew and B. Erik, "Big Data: the management revolution," Harvard Business Review, vol. 90, no. 10, pp. 68-128, 2012.

[4] N. R. Sanders, Big Data Driven Supply Chain Management, China Renmin University Press, 2015.

[5] Z. Liu and Q. Zhang, "Research overview of Big Data technology, Journal of Zhejiang University, vol. 6, article 1, 2014.

[6] M.-Q. Fan and R.-E. Ren, "Study on consumption structure of urban household based on heterogeneous preferences," China Soft Science, vol. 17, no. 10, pp. 37-46, 2007.

[7] C. W. Chase Jr., Demand-Driven Forecasting: A Structured Approach to Forecasting, John Wiley \& Sons, Hoboken, NJ, USA, 2013.

[8] BaiFenBai things internet. No.1 Shop: data-driven supply chain model, 2013, http://www.chinawuliu.com.cn/zhxw/201312/02/ 265336.shtml.

[9] J. Chen and Y. B. Xiao, "New developments and research prospects in supply chain management," Journal of University of Shanghai for Science and Technology, vol. 6, article 27, 2011. 
[10] N. R. Sanders, Big Data Driven Supply Chain Management: A Framework for Implementing Analytics and Turning Information Into Intelligence, Pearson Education, 2014.

[11] L. Wang and C. A. Alexander, "Big data driven supply chain management and business administration," American Journal of Economics and Business Administration, vol. 7, no. 2, pp. 60-67, 2015.

[12] J. Gantz and D. Reinsel, "Extracting value from chaos," IDC Research Report, 2011.

[13] L. L. Xue and H. G. Gang, "Big data system review," Science China Press, vol. 45, no. 1, pp. 1-44, 2015.

[14] J. Gantz and D. Reinsel, The Digital Universe in 2020: Big Data, Bigger Digital Shadows, and Biggest Growth in the Far East, IDC iView, IDC Analyze the Future, 2007.

[15] Z. T. Pei, “'Big Data' coming data revolution,” Chinses Journal QiuXian, pp. 60-61, 2012.

[16] W. L. Lian and J. X. Ming, "Innovative business models based on big data," China Industrial Economics, vol. 2, pp. 83-95, 2013.

[17] L. Jian and S. Hao, "Study the competitive intelligence system of closed-loop supply chain big data era," Library and Information Service, vol. 58, no. 2, pp. 96-101, 2014.

[18] B. T. Hazen, C. A. Boone, J. D. Ezell, and L. A. Jones-Farmer, "Data quality for data science, predictive analytics, and big data in supply chain management: an introduction to the problem and suggestions for research and applications," International Journal of Production Economics, vol. 154, pp. 72-80, 2014.

[19] N. E. Bowie and K. Jamal, "Privacy rights on the internet: selfregulation or government regulation?" Business Ethics Quarterly, vol. 16, no. 3, pp. 323-342, 2006.

[20] Z. H. Liming and Z. H. Jiangbo, "Mass customization of supply chain," Chinese Journal Science and Technology Management, vol. 24, no. 8, pp. 119-122, 2003.

[21] P. Russom, "Big Data Analytics," TDWI Best Practices Report, TDWI Research, Fourth Quarter 2011, 2011, http://tdwi.org/ research/2011/09/best-practices-report-q4-big-data-analytics/ asset.aspx.

[22] C. Loebbecke and A. Picot, "Reflections on societal and business model transformation arising from digitization and big data analytics: a research agenda," Journal of Strategic Information Systems, vol. 24, no. 3, pp. 149-157, 2015.

[23] D. Van Horn, A. Olewnik, and K. Lewis, "Design analytics: capturing, understanding, and meeting Customer needs using Big Data," in Proceedings of the International Design Engineering Technical Conferences and Computers and Information in Engineering Conference (ASME '12), pp. 863-875, Chicago, Ill, USA, August 2012.

[24] Z. Fang and P. Li, "The mechanism of "Big Data" impact on consumer behavior," American Journal of Industrial and Business Management, vol. 4, no. 1, pp. 45-50, 2014.

[25] M. L. Liu, "For electronic commerce: an empirical study of factors affecting consumer behavior," Network Economy and ECommerce, no. 7, 2006.

[26] D. Yang, "Under the "Water Army" marketing, how to get rid of the business 'information control,' 2015, http://view.news .qq.com/original/intouchtoday/n3403.html?pgv_ref=aio2015\& ptlang $=2052$.

[27] Z. Liu, "Perceptions of credibility of scholarly information on the Web," Information Processing and Management, vol. 40, no. 6, pp. 1027-1038, 2004.

[28] P. Weill and S. L. Woerner, "Thriving in an increasingly digital ecosystem," MIT Sloan Management Review, vol. 56, no. 4, pp. 27-34, 2015.
[29] W. Groves, J. Collins, M. Gini, and W. Ketter, "Agent-assisted supply chain management: analysis and lessons learned," Decision Support Systems, vol. 57, pp. 274-284, 2014.

[30] D. Opresnik and M. Taisch, "The value of big data in servitization," International Journal of Production Economics, vol. 165, pp. 174-184, 2015.

[31] E. Hofmann, "Big data and supply chain decisions: the impact of volume, variety and velocity properties on the bullwhip effect," International Journal of Production Research, pp. 1-19, 2015.

[32] K. H. Tan, Y. Z. Zhan, G. Ji, F. Ye, and C. Chang, "Harvesting big data to enhance supply chain innovation capabilities: an analytic infrastructure based on deduction graph," International Journal of Production Economics, vol. 165, pp. 223-233, 2015.

[33] T. Boyaci and G. Gallego, "Supply chain coordination in a market with customer service competition," Production and Operations Management, vol. 13, no. 1, pp. 3-22, 2004.

[34] T. Xiao, K. Shi, and D. Yang, "Coordination of a supply chain with consumer return under demand uncertainty," International Journal of Production Economics, vol. 124, no. 1, pp. 171180, 2010.

[35] Z. K. Weng, "Channel coordination and quantity discounts," Management Science, vol. 41, no. 9, pp. 1509-1522, 1995.

[36] G. Cachon, "Supply chain coordination with contracts," in Handbooks in Operations Research and Management Science, S. Graves and T. de Kok, Eds., pp. 229-340, North-Holland, Amsterdam, The Netherlands, 2003.

[37] C.-C. Hsieh, Y.-T. Liu, and W.-M. Wang, "Coordinating ordering and pricing decisions in a two-stage distribution system with price-sensitive demand through short-term discounting," European Journal of Operational Research, vol. 207, no. 1, pp. 142-151, 2010.

[38] G. P. Cachon and M. A. Lariviere, "Supply chain coordination with revenue-sharing contracts: strengths and limitations," Management Science, vol. 51, no. 1, pp. 30-44, 2005.

[39] G. Parthasarathi, S. P. Sarmah, and M. Jenamani, "Supply chain coordination under retail competition using stock dependent price-setting newsvendor framework," Operational Research, vol. 11, no. 3, pp. 259-279, 2011.

[40] S. Panda, "Coordinating two-echelon supply chains under stock and price dependent demand rate," Asia-Pacific Journal of Operational Research, vol. 30, no. 2, Article ID 1250051, 20 pages, 2013.

[41] S. Yang, K.-S. Hong, and C. Lee, "Supply chain coordination with stock-dependent demand rate and credit incentives," International Journal of Production Economics, vol. 157, no. 1, pp. 105-111, 2014.

[42] S. Hao and L. Jian, "Effect of private information leakage on copetition relationship among supply chain enterprises in Big Data Era," Journal of the China Society for Scientific and Technical Information, vol. 34, no. 1, pp. 53-65, 2015. 


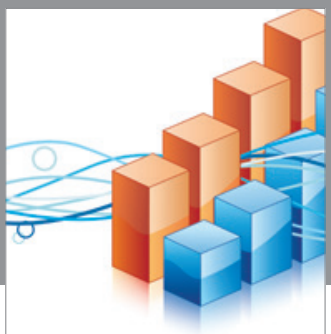

Advances in

Operations Research

vatem alat4

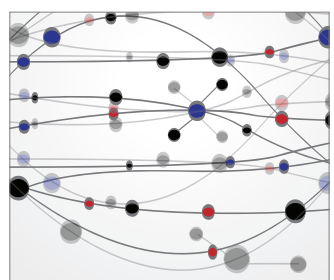

\section{The Scientific} World Journal
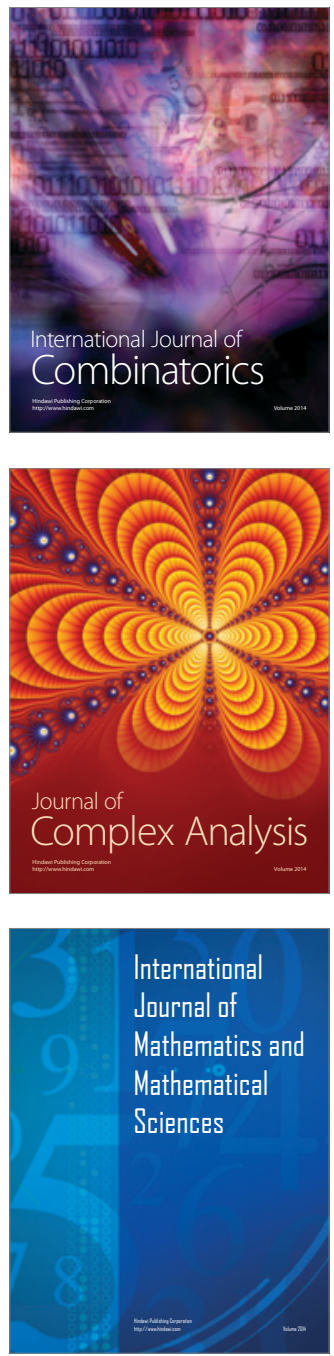
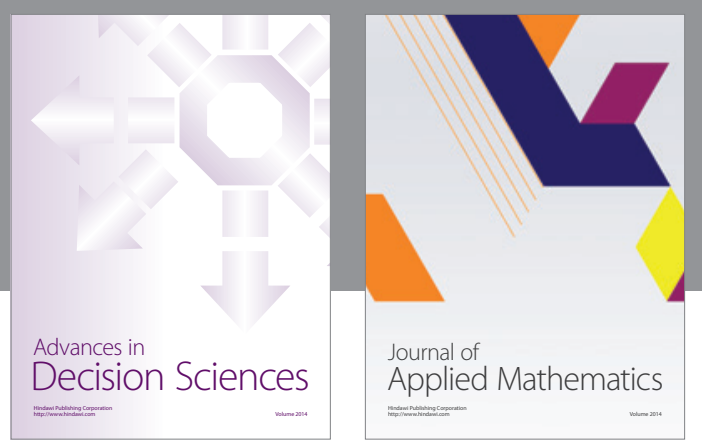

Algebra

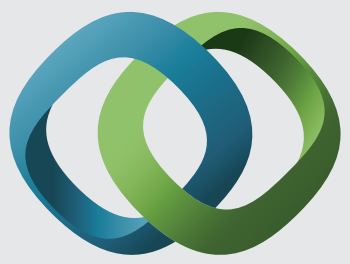

\section{Hindawi}

Submit your manuscripts at

http://www.hindawi.com
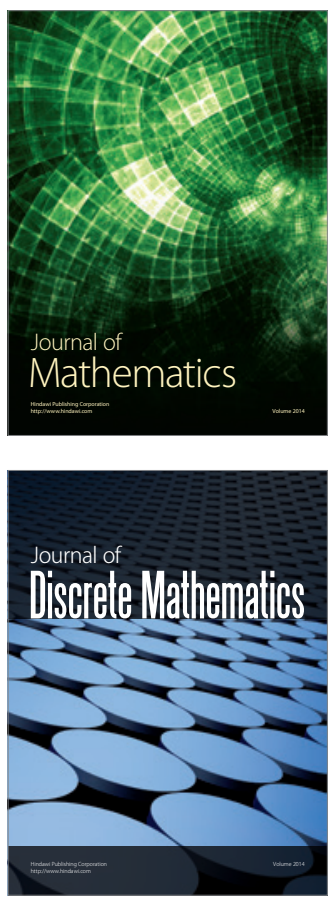

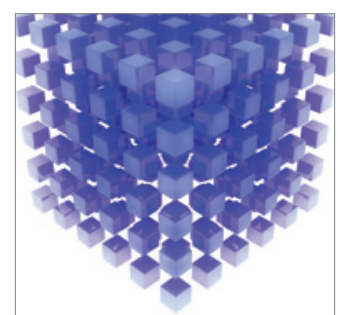

Mathematical Problems in Engineering
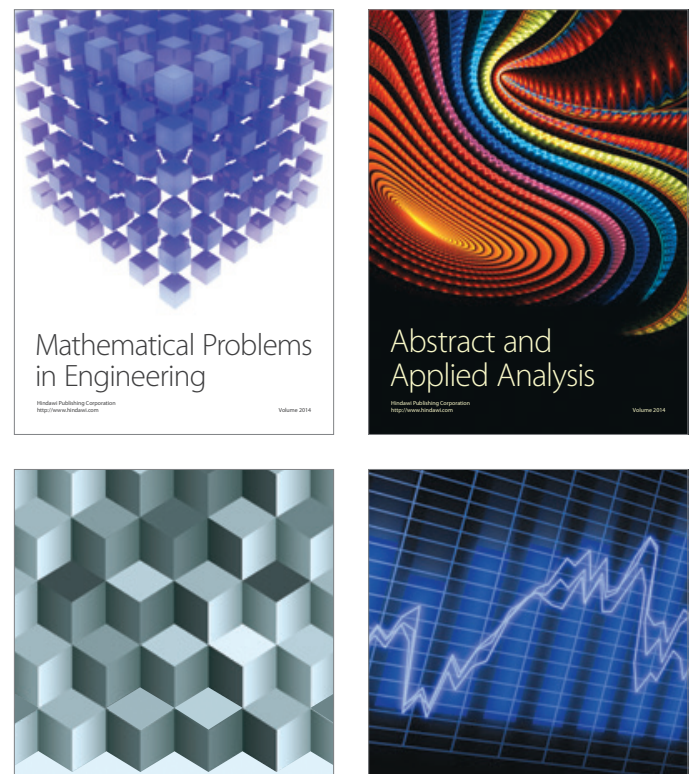

Journal of

Function Spaces

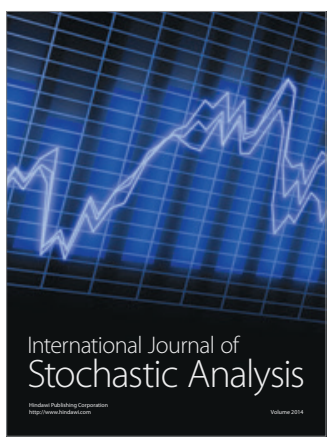

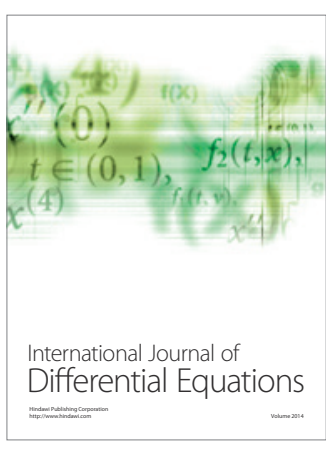
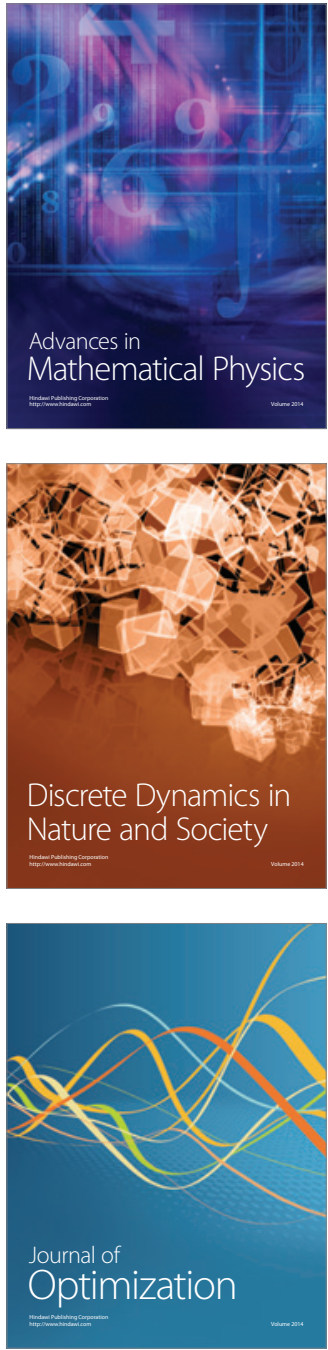